\title{
Industrialization of the mirror plate coatings for the ATHENA mission
}

Massahi, Sonny; Christensen, Finn Erland; Della Monica Ferreira, Desiree; Shortt, B.; Collon, M.; Sforzini, J.; Landgraf, B.; Hinze, F.; Aulhorn, S.; Biedermann, R.

Published in:

Optics for EUV, X-Ray, and Gamma-Ray Astronomy VIII

Link to article, DOI:

$10.1117 / 12.2274783$

Publication date:

2017

Document Version

Publisher's PDF, also known as Version of record

Link back to DTU Orbit

Citation (APA):

Massahi, S., Christensen, F. E., Della Monica Ferreira, D., Shortt, B., Collon, M., Sforzini, J., Landgraf, B. Hinze, F., Aulhorn, S., \& Biedermann, R. (2017). Industrialization of the mirror plate coatings for the ATHËNA mission. In S. L. O'Dell, \& G. Pareschi (Eds.), Optics for EUV, X-Ray, and Gamma-Ray Astronomy VIII [103991W] SPIE - International Society for Optical Engineering. Proceedings of SPIE - The International Society for Optical Engineering https://doi.org/10.1117/12.2274783

\section{General rights}

Copyright and moral rights for the publications made accessible in the public portal are retained by the authors and/or other copyright owners and it is a condition of accessing publications that users recognise and abide by the legal requirements associated with these rights.

- Users may download and print one copy of any publication from the public portal for the purpose of private study or research.

- You may not further distribute the material or use it for any profit-making activity or commercial gain

- You may freely distribute the URL identifying the publication in the public portal 


\section{Industrialization of the mirror plate coatings for the ATHENA mission}

S. Massahi, F. E. Christensen, D. D. M. Ferreira, B. Shortt, M. Collon, et al.

S. Massahi, F. E. Christensen, D. D. M. Ferreira, B. Shortt, M. Collon, J. Sforzini, B. Landgraf, F. Hinze, S. Aulhorn, R. Biedermann, "Industrialization of the mirror plate coatings for the ATHENA mission," Proc. SPIE 10399, Optics for EUV, X-Ray, and Gamma-Ray Astronomy VIII, 103991W (29 August 2017); doi: 10.1117/12.2274783

SPIE Event: SPIE Optical Engineering + Applications, 2017, San Diego, California, United States 


\title{
Industrialization of the mirror plate coatings for the Athena mission
}

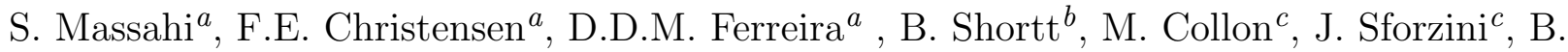

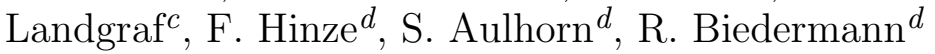

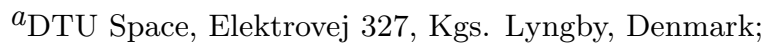 \\ ${ }^{b}$ European Space Research and Technology Centre (ESTEC), Keplerlaan 1, Noordwijk, The Netherlands;

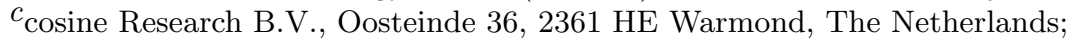

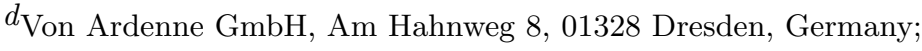

\begin{abstract}
In the frame of the development of the Advanced Telescope for High-ENergy Astrophysics (Athena) mission, currently in phase A, ESA is continuing to mature the optics technology and the associated mass production techniques. These efforts are driven by the programmatic and technical requirement of reaching TRL 6 prior to proposing the mission for formal adoption (planned for 2020). A critical part of the current phase A preparation activities is addressing the industrialization of the Silicon Pore Optics mirror plates coating. This include the transfer of the well-established coating processes and techniques, performed at DTU Space, to an industrial scale facility suitable for coating the more than 100,000 mirror plates required for Athena. In this paper, we explain the considerations for the planned coating facility including, requirement specification, equipment and supplier selection, preparing the coating facility for the deposition equipment, designing and fabrication.
\end{abstract}

Keywords: Athena, Silicon Pore Optics (SPO), Multilayer Deposition, DC Magnetron Sputtering, XRR, X-ray Optics, DTU Space

\section{INTRODUCTION}

A proper, well-defined, thin-film coating deposited on the mirror plates is critical for the scientific objectives of the Athena mission. The energy range to be covered by Athena stretches from $300 \mathrm{eV}$ to $12 \mathrm{keV}$ [1]. Using mirror plates only composed of Silicon and Silicon Dioxide will not fulfill the throughput requirement for the Athena mission. Introducing a well designed thin-film composed of a high density material and a low density material will increase the throughput of the telescope ${ }^{[2,3,4]}$. This is presented experimentally for an optimized multilayer composed of Iridium and Boron Carbide irradiated in the energy range from 3-10 keV at fixed grazing incidence of 0.6 degrees ${ }^{[5]}$ and several other thin-film designs ${ }^{[6]}$ measured at the PTB laboratory, BESSY II.

The surface roughness of the deposited thin-film shall be lower than $0.5 \mathrm{~nm}$ and the interface roughness shall be lower than $0.4 \mathrm{~nm}$. Such results have been shown in ${ }^{[7]}$. The reflection of X-rays occurs at the interface and the surface of the thin-films and rough surfaces will result in scattering and loss of throughput ultimately reducing the effective area.

In the on-going technology development for the Athena mission, a key objective is demonstrating the scaling up of the SPO production process from R\&D levels to the high volumes needed for the flight implementation phase ${ }^{[8]}$. The direct current (DC) magnetron sputter facility located at DTU Space, Denmark, has been serving as the base thin-film deposition technique for the development of the Athena optics. As a result of the up scaling, the mirror capacity and deposition throughput of the DTU Space sputter unit succumbs and a new deposition unit is required. Furthermore, the shipment of mirror plates from the plate supplier located in the Netherlands and the United Kingdom, to DTU Space located in Denmark and then to cosine located in the Netherlands, becomes time demanding and may result in a reduction of mirror plate cleanliness. Consequently it was decided to centralize the coating facility and the cleaning/stacking facility at cosine ${ }^{[9]}$.

Further author information: (Send correspondence to S. Massahi)

S. Massahi: E-mail: sonmas@space.dtu.dk, Telephone: +4531241456

Optics for EUV, X-Ray, and Gamma-Ray Astronomy VIII, edited by Stephen L. O'Dell, Giovanni Pareschi, Proc. of SPIE Vol. 10399, 103991W · C 2017 SPIE - CCC code: 0277-786X/17/\$18 - doi: 10.1117/12.2274783 
The coating facility shall be capable of processing 300 mirror plates per day to prove the concept of producing approximately 100,000 flight model plates over the two years flight production period. The production of the mirror plates for the Athena mission is planned to span from 2023 to $2025{ }^{[10]}$.

\section{SELECTION OF SUPPLIER AND DEPOSITION TECHNIQUE}

Selecting a thin-film deposition system, it is necessary to fully understand the purpose of the machine/facility and be compliant with the requirements of the end product ${ }^{[11]}$. The X-ray reflecting coating requirements for the Athena mission are driven by maximizing the plate throughput and at the same time maintaining a high film quality. The throughput, mainly depending on the deposition method, the chamber capacity and the pumping efficiency, is discussed in section 4 .

The timeline for the acquisition and commissioning of the new chamber is presented in figure 1 . We present the main steps in the process of designing, purchasing and commissioning an vacuum deposition system. Prior market research, a list of thin-film requirements was established based on the studies being carried out at DTU Space, cosine and European Space Agency (ESA). This list was circulated to several suppliers around the world. A few suppliers provided a quotation of a thin-film deposition system that in principle would meet the requirements established by DTU Space. After the market-research an open tender process was initiated. The production time including factory acceptance testing is approximately 8-9 month. The foreseen calibration of the chamber includes uniformity mapping, determination of deposition rates and more technical aspects presented here. Once the thin-film process performed at DTU Space is fully established in the new coating system, a commissioning is initiated.

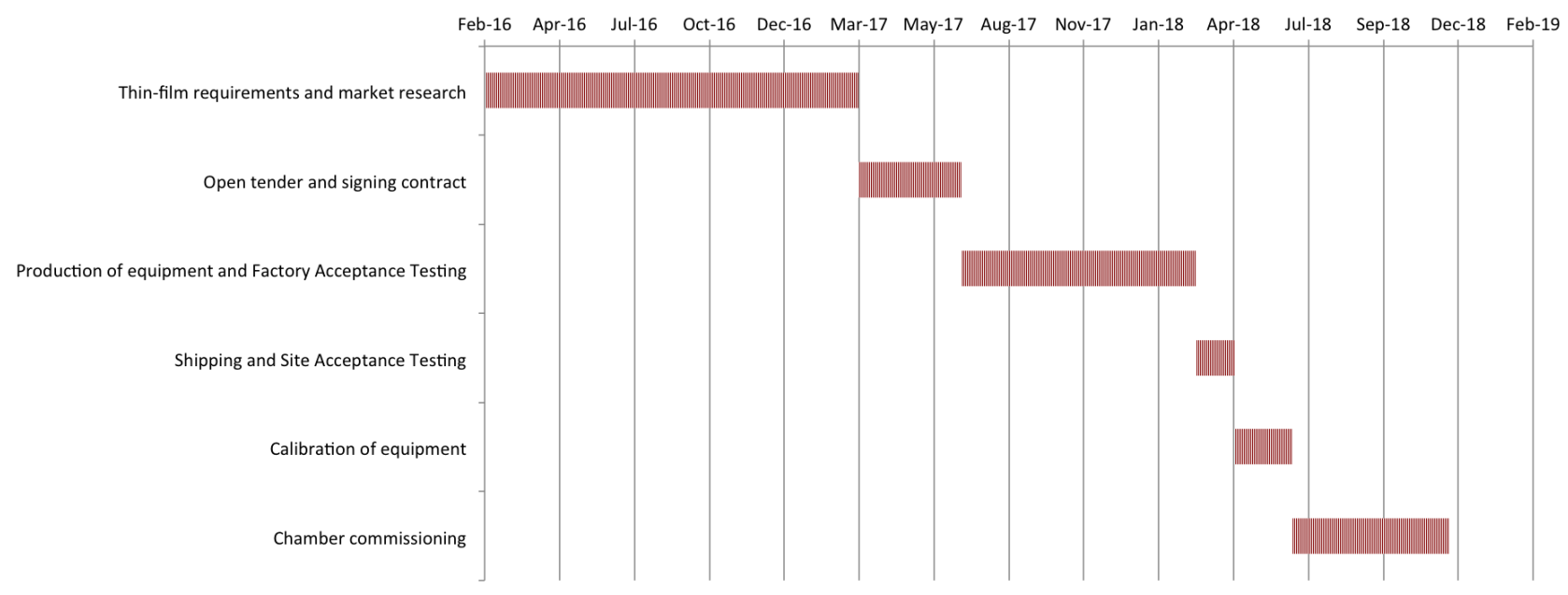

Figure 1: Gantt chart of the acquisition, testing, installation and commissioning process.

\subsection{Deposition method and considerations}

DC magnetron sputtering has been adopted for depositing reflective coatings on numerous X-ray telescopes, and as such is the method with a good track record for the application at hand. For the Advanced X-ray Astrophysics Facility (AXAF), a detailed study of deposition techniques for X-ray optics was performed [12]. In this study it is presented that magnetron sputtering outperformed evaporative coatings mainly due to higher energetic sputtered atoms resulting in a higher mobility, hence a more dense films. This is confirmed by a study that compares magnetron sputtering to electron-beam evaporation and thermal evaporation ${ }^{[13]}$, where numerous advantages of magnetron sputtering mentioned are, excellent uniformity on large-area substrates, high adhesion of the films to the substrate, ease of sputtering any kind of metal, compound, low cost, high reliability, ease of 
process control and high deposition rates. These are extremely important aspects for the thin-film requirements for Athena and DC magnetron sputtering is considered the best approach.

Likewise the optics for the Nuclear Spectroscopic Telescope Array (NuSTAR), the Pt/C and W/Si multilayer thin-films, were successfully deposited using the DC magnetron sputtering technique ${ }^{[14]}$. Applicability of $\operatorname{Ir} / \mathrm{B}_{4} \mathrm{C}$ layers to Athena mission showed to fulfill the quality requirements.

\subsection{Market research}

With the deposition method in place, we contacted several thin-film deposition companies in the world who offers DC magnetron systems. Three different types of systems was presented to us; cluster coater, drum coaters, inline coaters, from which the cluster tools where disregarded due to the high price and the short-coming on the throughput requirement.

Out of the large group of companies, comparison and trade-off tables provided a clear overview ultimately resulting in a down selection phase. Based on several practical and technical parameters such as, offered system, target-to-substrate flexibility, pump-down time, pre-purchase testing, throughput, cost and more, scores were given to the remaining companies. Von Ardenne scored highest in the overall assessment however company B was given similar scores as. The main difference being the flexibility of performing a pre-purchase test where Von Ardenne was the only company able to perform the test within a reasonable price and time schedule.

Von Ardenne won the tender with DTU Space and is the chosen company for the task at hand.

\section{SYSTEM DESIGN}

The German company, Von Ardenne, offers a DC magnetrons sputtering drum coater, model BS1200S, which is a custom made device based on the drum coater operating at DTU Space. An illustration of the drum coater can be observed in figure 2 . The process chamber will have four process stations, where initially two magnetrons and one inverse sputter etching unit will accommodate three of them. The right hand side image in figure 2 shows a technical drawing of the chamber seen from the top. There are 14 holding spots for the carriers, where the sputter throwing distance can be varied.

For a more efficient and faster pumpdown utilizing a bakeout system is desirable. By heating the chamber surface to $>90^{\circ} \mathrm{C}$, the moisture sticking to the chamber surface evaporates and is removed from the system through the pumping system.

The back-out unit uses the chamber wall integrated water pipes with an external high temperature control unit to heat the wall with $140^{\circ} \mathrm{C}$ hot water pressurized to at least 5 bar. The wall will be insulated to prevent heat losses and keep the outside parts cold due to safety issues and to prevent the heating of the surrounding. The bake-out feature will be controlled by system software.

\subsection{Flexibility of target-to-substrate distance}

The target-to-substrate-distance (TSD) is designed so the mirrors can be placed at three different positions in the carrousel. The TSD available are: $100 \mathrm{~mm}, 125 \mathrm{~mm}$ and $150 \mathrm{~mm}$. The current process at DTU Space is performed at a TSD of $\sim 155 \mathrm{~mm}$. As a result of a shorter throwing distance, the deposition rate increases due to less scattering of sputtered atoms and changes in the angular distribution of the sputtered atoms ${ }^{[15]}$. This option may prove significantly important regarding the production time however studies suggest that the film uniformity may worsen due to the angular distribution ${ }^{[16]}$. The optimal angular distribution of the sputtered atoms and throwing distance will be determined in the foreseen calibration of the deposition system.

\subsection{Magnetron design}

The planar Small Standard Magnetron (SSM) sputter source is a key-component of Von Ardenne company's SSM type series of rectangular standard single sputter sources operated in DC mode. The magnetrons are vertically arranged at the outer circumference of the process chamber, see figure 2 . The flanges of the magnetrons are designed as a door for easy access for maintenance and replacement of targets. Furthermore, it will be possible to install the type of magnetron that is currently practiced at DTU Space. Compared to the existing sputter unit located at DTU Space, which has the full magnetron placed inside the chamber, the contamination exposed surface area is much smaller. This is a great advantage in terms of chamber preparation, pump-down 


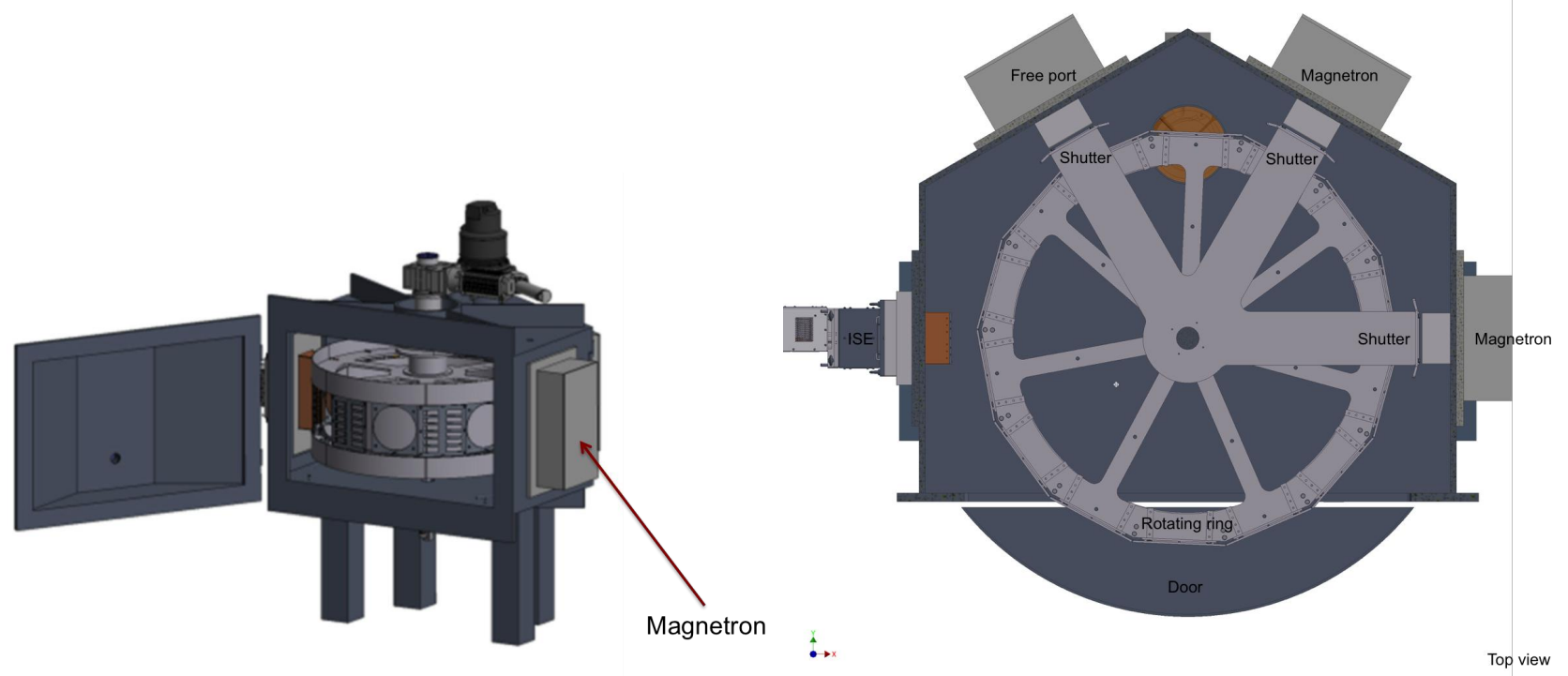

Figure 2: Sketches of the custom designed drum coater, BS1200S. (c) VON ARDENNE Corporate Archive

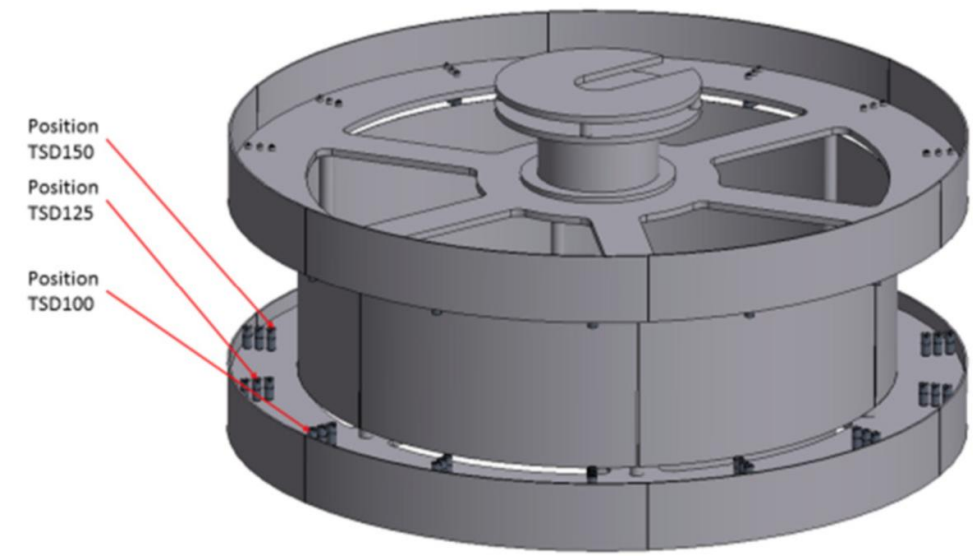

Figure 3: Illustration of the carrier holding carrousel. Three different target-to-substrate distances are applicable. (C) VON ARDENNE Corporate Archive

time and maintenance time. The SSM source accommodates targets that are $600 \mathrm{~mm}$ long and $108 \mathrm{~mm}$ wide, which foreseen for Athena will be bonded to a copper backing plate with the targets being divided into tiles. An illustration of a SSM with target material and honey-comb collimation is shown in figure 4.

\subsection{Substrate pre-treatment}

For a defined surface cleaning/pre-treatment an Inverse Sputter Etcher (ISE) is foreseen for the deposition chamber. The ISE will enable a surface cleaning prior thin-film deposition without breaking vacuum and exposing the surface for atmospheric contamination. Prior thin-film deposition the SPO surface is patterned with photoresist. In between the striped photoresist lines, referred to as the X-ray reflecting surface, is the $\mathrm{SiO}_{2}$-surface upon where the thin-film will be deposited. This surface contains remnants from the photolithography process, which induces higher roughness in the deposited thin-films. The morphology of the X-ray reflecting surface is shown in ${ }^{[17]}$. Here it was shown that these photoresist remnants were removable through plasma ashing. The ISE will 


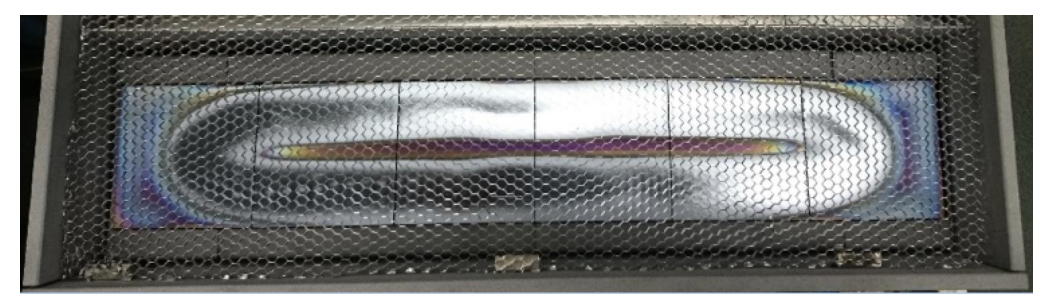

Figure 4: Image of an SSM accomodating target material divided into several tiles. A honey comb collimation grid is placed $50 \mathrm{~mm}$ from the target surface. (C) VON ARDENNE Corporate Archive

process Oxygen and Argon gas atoms which are sputtered onto the SPO surface, the Oxygen will remove the organic material and form $\mathrm{H}_{2} \mathrm{O}, \mathrm{CO}_{2}$ and other products. The contamination removal rate will be determined once the deposition system is calibrated. The component will be installed in one of the free process stations. It comes with an RF power supply, matchbox and an RF filter for the DC generator.

\section{PRODUCTIVITY ESTIMATE}

This section provides a rough estimate of the mirror plate coating production based on the foreseen deposition system described in the latter section. The dimensions may vary slightly in the detailed design phase but is not expected to affect the presented estimate significantly. The productivity estimate includes all aspects of the thin-film deposition process from the point where the plates are mounted into the deposition chamber to the point where they are dismounted. This includes numerous steps that are presented in table 2 . The process times are given in minutes and are based on the experience gained on the deposition process performed at DTU Space and verified by the specialists at Von Ardenne.

\subsection{Optical design for Athena: Mirror dimensions}

The mirror dimension varies as a function of radius in the Athena optics. In the inner radius, the mirrors shall reflect X-rays at the lowest grazing incidence angle with respect to the full optics. To avoid a longer X-ray beam footprint than the mirror length, the mirrors are long, compared to the outer radius where the mirrors are shorter due to the higher grazing incidence. The current Athena baseline design consists of 20 rows with the most updated mirror dimension design presented in table 1. The mounting area is based on the Von Ardenne carrier size assuring uniformity better than $5 \%$. The number of mounted mirrors has been estimated from the mirror dimension and additionally adding $10 \mathrm{~mm}$ in both the vertical and horizontal direction between each mirror on the carrier. A sketch of the foreseen mirror placement on the carriers for row 1,8 and 20 is illustrated in figure 5 .

\subsection{Process steps, assumptions and calculations}

Process step 1, 3, 4, 5 and 7 presented in table 2, is independent of the number of mirrors and the mirror dimension, with the most time-consuming step being reaching the base-pressure. Process step 2 and 8 depends on the number of mirrors that can be mounted on the carrier. The mounting of the samples onto the carrier is currently performed by hand. For the flight production an automated handling of the plates is foreseen and this requires a technique to move a plate and place it on the carrier. For the calculation, 15 seconds have been appointed for placing a single mirror on the carrier and 30 seconds for placing the carrier inside the drum. Obviously, by purchasing a second set of carriers it enables us to reduce the mirror-to-carrier mounting time, as this can be done while the previous batch is being processed.

The thin-film deposition time mainly depends on the thin-film design, and the pre-sputtering time of five minutes per target becomes less significant in the calculations. The pre-sputtering removes any oxidized layer 


\begin{tabular}{|c|c|c|c|c|c|c|c|c|}
\hline $\begin{array}{c}\text { Row } \\
\text { number }\end{array}$ & \multicolumn{2}{|c|}{$\begin{array}{c}\text { Mirror } \\
\text { Dimension } \\
\text { (mm) }\end{array}$} & \multicolumn{2}{c|}{$\begin{array}{c}\text { Mounting } \\
\text { area on carrier } \\
\text { (mm) }\end{array}$} & $\begin{array}{c}\text { Number of mounted } \\
\text { mirrors in the horizontal } \\
\text { and vertical direction }\end{array}$ & $\begin{array}{c}\text { Number } \\
\text { of mirrors } \\
\text { per carrier }\end{array}$ & $\begin{array}{c}\text { Total } \\
\text { mirrors } \\
\text { per batch }\end{array}$ \\
\hline- & Width & Length & Width & Length & Vertical & Horizontal & - & - \\
\hline 1 & 37,1 & 101,5 & 310 & 260 & 6 & 2 & 12 & 168 \\
\hline 2 & 50,2 & 83,4 & 310 & 260 & 5 & 2 & 10 & 140 \\
\hline 3 & 49,8 & 70,8 & 310 & 260 & 5 & 3 & 15 & 210 \\
\hline 4 & 49,6 & 61,5 & 310 & 260 & 5 & 3 & 15 & 210 \\
\hline 5 & 89,4 & 54,3 & 310 & 260 & 3 & 4 & 12 & 168 \\
\hline 6 & 82,5 & 48,7 & 310 & 260 & 3 & 4 & 12 & 168 \\
\hline 7 & 77,6 & 44,1 & 310 & 260 & 3 & 4 & 12 & 168 \\
\hline 8 & 86,9 & 40,3 & 310 & 260 & 3 & 5 & 15 & 210 \\
\hline 9 & 82,1 & 37,1 & 310 & 260 & 3 & 5 & 15 & 210 \\
\hline 10 & 90,2 & 34,4 & 310 & 260 & 3 & 5 & 15 & 210 \\
\hline 11 & 85,5 & 32,0 & 310 & 260 & 3 & 6 & 18 & 252 \\
\hline 12 & 92,8 & 30,0 & 310 & 260 & 3 & 6 & 18 & 252 \\
\hline 13 & 88,3 & 28,2 & 310 & 260 & 3 & 6 & 18 & 252 \\
\hline 14 & 94,8 & 26,6 & 310 & 260 & 2 & 7 & 14 & 196 \\
\hline 15 & 90,6 & 25,2 & 310 & 260 & 3 & 7 & 21 & 294 \\
\hline 16 & 87,1 & 23,9 & 310 & 260 & 3 & 7 & 21 & 294 \\
\hline 17 & 92,5 & 22,8 & 310 & 260 & 3 & 7 & 21 & 294 \\
\hline 18 & 89,1 & 21,7 & 310 & 260 & 3 & 8 & 24 & 336 \\
\hline 19 & 94,1 & 20,8 & 310 & 260 & 2 & 8 & 16 & 224 \\
\hline 20 & 90,9 & 19,9 & 310 & 260 & 3 & 8 & 24 & 336 \\
\hline
\end{tabular}

Table 1: Mirror dimensions for each row of the current design for the Athena optics. The total number of mirrors per batch is shown based on the Von Ardenne carrier design. The total number of carriers, which define a batch is 14 .

Row 1

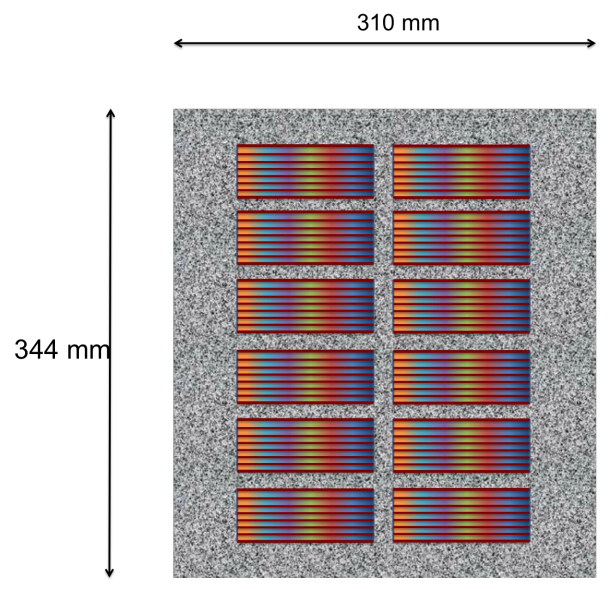

Row 8

Row 20

Figure 5: Foreseen mirror plate configuration on the Von Ardenne carrier design.

on the target surface for a stable and clean sputtering process. The pre-sputtering of 5 minutes is sufficient to remove contamination from the target surface. Prior and during the pre-sputtering, shutters, which are metallic plates will be moved into the sputtering path from the target to the substrate, hence collecting the contaminated material. This will ensure a clean X-ray reflecting coating.

The single bilayer used for the throughput calculation presented in table 3 , represents the optimized Athena baseline with a bottom layer of $10.0 \mathrm{~nm}$ Ir and a top-layer of $8.0 \mathrm{~nm} \mathrm{~B}{ }_{4} \mathrm{C}$. The proposed thin-film multilayer design consists of single bilayers and linear graded multilayer thinfilms and the estimated productivity is shown in table 4. This optimized multilayer coating design is presented in ${ }^{[18]}$ and would improve the effective area at $6 \mathrm{keV}$ with approximately $46 \%$ compared to the single bilayer design. The last productivity table presented, 


\begin{tabular}{|c|c|c|c|}
\hline Process step & Description & $\begin{array}{l}\text { Process time per batch } \\
\text { (min) }\end{array}$ & Comment \\
\hline 1 & Chamber preparation & 19 & \\
\hline 1.1 & Removal of dust particles & 15 & Nitrogen blow/Vacuum clean \\
\hline 1.2 & Inspection of targets & 2 & Visual \\
\hline 1.3 & Inspection of magnetrons & 2 & Visual + electrical parameters \\
\hline 2 & Mounting & 49 & \\
\hline 2.1 & Samples on carriers & 42 & 15 seconds based on current mounting method \\
\hline 2.2 & Carriers in chamber & 7 & 30 seconds per carrier \\
\hline 3 & Pre-pump down preparation & 1 & \\
\hline 3.1 & Cleaning surfaces with IPA & 1 & Remove particles \\
\hline 4 & Pump-down & 240 & \\
\hline 4.1 & Reach base-pressure & 240 & Less than $2 \times 10^{\wedge}-6$ Torr including bake-out \\
\hline 5 & Substrate pre-treatment & 10 & \\
\hline 5.1 & Sputter etching & 10 & Removal of organic material on reflective surface \\
\hline 6 & Thin-film deposition & 107 & \\
\hline 6.1 & Reach working gas pressure & 2 & Order of $3 \times 10^{\wedge}-3$ Torr \\
\hline 6.2 & Pre-sputtering & 10 & 5 minutes per material \\
\hline 6.3 & Deposition time & 95 & Based on deposition rate of DTU Space system \\
\hline 7 & Pump-up & 10 & \\
\hline 7.1 & Reach atmosperic pressure & 10 & Venting with Nitrogen \\
\hline 8 & Dismounting & 49 & \\
\hline 8.1 & Carriers in chamber & 7 & 30 seconds per carrier \\
\hline 8.2 & Samples on carriers & 42 & 15 seconds based on current mounting method \\
\hline Total time & & 485 & \\
\hline
\end{tabular}

Table 2: Thin-film deposition process steps. This is a specific case for the baseline coating consisting of a single bilayer, row 1, for Athena.

table 5, is for a thin-film design only consisting of a single layer of Iridium. This will reduce the effective area of the telescope in the lower energy spectrum $(<5 \mathrm{keV})$, which is otherwise boosted by the lower density material.

The applied dynamic deposition rate (DDR) for Ir and $\mathrm{B}_{4} \mathrm{C}$ is $2.1 \mathrm{~nm} \cdot \mathrm{m} / \mathrm{min}$ and $0.53 \mathrm{~nm} \cdot \mathrm{m} / \mathrm{min}$, respectively. These numbers are based on the derived power density of $3.1 \mathrm{~W} / \mathrm{cm}^{2}$ for Ir and a power density of 5.17 $\mathrm{W} / \mathrm{cm}^{2}$ for $\mathrm{B}_{4} \mathrm{C}$ for the targets installed in the DTU Space deposition chamber. These rates emanate from a throwing distance of $155 \mathrm{~mm}$, including honey-comb collimation installed in the TSD and a working gas pressure of 2.5 mTorr. Similar or better DDR's are foreseen from the Von Ardenne chamber.

The coating length of the Von Ardenne drum coater is $4774 \mathrm{~mm}$ corresponding to a full rotation. One full rotation will result in a single layer of either Ir or $\mathrm{B}_{4} \mathrm{C}$ and is thereby the nature of the calculated deposition times, given in table 3-5. In the case of the multilayer design, table 4, the total thin-film thickness of each material is presented.

It is unlikely that downtime can be avoided completely due to magnetron maintenance and other unforeseen failures, which is reflecting the yield of $85 \%$ in the tables. With the foreseen Von Ardenne magnetrons this may be not be the case as their magnetrons are designed from scratch to endure much more stringent $24 / 7$ coating conditions. However to provide a margin in the estimation the yield of $85 \%$ is included in the calculations.

The total coating time per ring is given by equation 1 .

Total coating time per ring $=\frac{\text { Actual number of plates per ring }}{\text { Total mirrors per batch }}($ Preparation time + Deposition time per batch $)$

The total coating time for all 20 rows given in days are based on a continuous flow of mirror production, implying that when one batch is completed the next is processed. This will demand operators engaged $24 / 7$, which is currently not planned for the Athena flight production.

As a result of this productivity estimate, performing the thin-film deposition of the latter mentioned designs, having a second deposition chamber will be key to ensure a successful flight production of the Athena optics. Unforeseen down-time can occur do to component failures resulting in replacements with long lead times. 


\begin{tabular}{|c|c|c|c|c|c|c|c|c|c|}
\hline Row & $\begin{array}{r}\text { Total } \\
\text { th }\end{array}$ & & $\begin{array}{c}\text { Deposition time } \\
\text { per batch } \\
\text { (min) }\end{array}$ & $\begin{array}{c}\text { Preparation } \\
\text { time } \\
\text { (min) }\end{array}$ & $\begin{array}{c}\text { Number of } \\
\text { mirror } \\
\text { modules }\end{array}$ & $\begin{array}{l}\text { Number } \\
\text { of plates } \\
\text { per ring }\end{array}$ & $\begin{array}{c}\text { Yield } \\
(\%)\end{array}$ & $\begin{array}{c}\text { Actual number } \\
\text { of plates } \\
\text { per ring }\end{array}$ & $\begin{array}{c}\text { Total coating } \\
\text { time per ring } \\
\text { (h) }\end{array}$ \\
\hline- & Ir & $\mathrm{B}_{4} \mathrm{C}$ & - & - & - & - & - & - & - \\
\hline 1 & 10.0 & 8.0 & 95 & 390 & 120 & 4200 & 85 & 4941 & 242 \\
\hline 2 & 10.0 & 8.0 & 95 & 376 & 120 & 4200 & 85 & 4941 & 282 \\
\hline 3 & 10.0 & 8.0 & 95 & 411 & 144 & 5040 & 85 & 5929 & 244 \\
\hline 4 & 10.0 & 8.0 & 95 & 411 & 168 & 5880 & 85 & 6918 & 278 \\
\hline 5 & 10.0 & 8.0 & 95 & 390 & 120 & 4200 & 85 & 4941 & 242 \\
\hline 6 & 10.0 & 8.0 & 95 & 390 & 144 & 5040 & 85 & 5929 & 291 \\
\hline 7 & 10.0 & 8.0 & 95 & 390 & 168 & 5880 & 85 & 6918 & 339 \\
\hline 8 & 10.0 & 8.0 & 95 & 411 & 168 & 5880 & 85 & 6918 & 278 \\
\hline 9 & 10.0 & 8.0 & 95 & 411 & 192 & 6720 & 85 & 7906 & 320 \\
\hline 10 & 10.0 & 8.0 & 95 & 411 & 192 & 6720 & 85 & 7906 & 320 \\
\hline 11 & 10.0 & 8.0 & 95 & 432 & 216 & 7560 & 85 & 8894 & 316 \\
\hline 12 & 10.0 & 8.0 & 95 & 432 & 216 & 7560 & 85 & 8894 & 316 \\
\hline 13 & 10.0 & 8.0 & 95 & 432 & 240 & 8400 & 85 & 9882 & 351 \\
\hline 14 & 10.0 & 8.0 & 95 & 404 & 240 & 8400 & 85 & 9882 & 424 \\
\hline 15 & 10.0 & 8.0 & 95 & 453 & 264 & 9240 & 85 & 10871 & 338 \\
\hline 16 & 10.0 & 8.0 & 95 & 453 & 288 & 10080 & 85 & 11859 & 374 \\
\hline 17 & 10.0 & 8.0 & 95 & 453 & 288 & 10080 & 85 & 11859 & 374 \\
\hline 18 & 10.0 & 8.0 & 95 & 474 & 316 & 11060 & 85 & 13012 & 370 \\
\hline 19 & 10.0 & 8.0 & 95 & 418 & 312 & 10920 & 85 & 12847 & 496 \\
\hline 20 & 10.0 & 8.0 & 95 & 474 & 336 & 11760 & 85 & 13835 & 398 \\
\hline Total & - & - & - & - & 4252 & 148820 & - & 175082 & 275 days \\
\hline
\end{tabular}

Table 3: Productivity estimate based on the single bilayer baseline thin-film design.

\begin{tabular}{|c|c|c|c|c|c|c|c|c|c|}
\hline Row & \multicolumn{2}{|c|}{$\begin{array}{c}\text { Total thin-film } \\
\text { thickness } \\
\text { (nm) }\end{array}$} & $\begin{array}{c}\text { Deposition time } \\
\text { per batch } \\
\text { (min) }\end{array}$ & $\begin{array}{c}\text { Preparation } \\
\text { time } \\
\text { (min) }\end{array}$ & $\begin{array}{c}\text { Number of } \\
\text { mirror } \\
\text { modules }\end{array}$ & $\begin{array}{c}\text { Number } \\
\text { of plates } \\
\text { per ring }\end{array}$ & $\begin{array}{c}\text { Yield } \\
\text { (\%) }\end{array}$ & $\begin{array}{c}\text { Actual number } \\
\text { of plates } \\
\text { per ring }\end{array}$ & $\begin{array}{c}\text { Total coating } \\
\text { time per ring } \\
\text { (h) }\end{array}$ \\
\hline- & $\mathrm{Ir}$ & $\mathrm{B}_{4} \mathrm{C}$ & - & - & - & - & - & - & - \\
\hline 1 & 10.0 & 8.0 & 95 & 390 & 120 & 4200 & 85 & 4941 & 242 \\
\hline 2 & 10.0 & 8.0 & 95 & 376 & 120 & 4200 & 85 & 4941 & 282 \\
\hline 3 & 10.0 & 8.0 & 95 & 411 & 144 & 5040 & 85 & 5929 & 244 \\
\hline 4 & 10.0 & 8.0 & 95 & 411 & 168 & 5880 & 85 & 6918 & 278 \\
\hline 5 & 15.4 & 16.1 & 180 & 390 & 120 & 4200 & 85 & 4941 & 285 \\
\hline 6 & 36.0 & 47.0 & 505 & 390 & 144 & 5040 & 85 & 5929 & 537 \\
\hline 7 & 35.0 & 45.4 & 489 & 390 & 168 & 5880 & 85 & 6918 & 615 \\
\hline 8 & 47.5 & 64.3 & 687 & 411 & 168 & 5880 & 85 & 6918 & 604 \\
\hline 9 & 46.0 & 62.0 & 663 & 411 & 192 & 6720 & 85 & 7906 & 680 \\
\hline 10 & 41.5 & 55.3 & 593 & 411 & 192 & 6720 & 85 & 7906 & 636 \\
\hline 11 & 41.5 & 55.3 & 593 & 432 & 216 & 7560 & 85 & 8894 & 615 \\
\hline 12 & 40.0 & 53.0 & 568 & 432 & 216 & 7560 & 85 & 8894 & 600 \\
\hline 13 & 37.0 & 48.5 & 521 & 432 & 240 & 8400 & 85 & 9882 & 635 \\
\hline 14 & 35.5 & 46.3 & 498 & 404 & 240 & 8400 & 85 & 9882 & 767 \\
\hline 15 & 35.5 & 46.3 & 498 & 453 & 264 & 9240 & 85 & 10871 & 586 \\
\hline 16 & 34.0 & 44.0 & 474 & 453 & 288 & 10080 & 85 & 11859 & 633 \\
\hline 17 & 32.5 & 41.8 & 450 & 453 & 288 & 10080 & 85 & 11859 & 617 \\
\hline 18 & 32.5 & 41.8 & 450 & 474 & 316 & 11060 & 85 & 13012 & 601 \\
\hline 19 & 32.5 & 41.8 & 450 & 418 & 312 & 10920 & 85 & 12847 & 840 \\
\hline 20 & 32.5 & 41.8 & 450 & 474 & 336 & 11760 & 85 & 13835 & 647 \\
\hline Total & - & - & - & - & 4252 & 148820 & - & 175082 & 456 days \\
\hline
\end{tabular}

Table 4: Productivity estimate based on the optimized multilayer thin-film design. 


\begin{tabular}{|c|c|c|c|c|c|c|c|c|}
\hline Row & $\begin{array}{c}\text { Total thin-film } \\
\text { thickness } \\
(\mathrm{nm})\end{array}$ & $\begin{array}{c}\text { Deposition time } \\
\text { per batch } \\
(\text { min })\end{array}$ & $\begin{array}{c}\text { Preparation } \\
\text { time } \\
\text { (min) }\end{array}$ & $\begin{array}{c}\text { Number of } \\
\text { mirror } \\
\text { modules }\end{array}$ & $\begin{array}{l}\text { Number } \\
\text { of plates } \\
\text { per ring }\end{array}$ & $\begin{array}{c}\text { Yield } \\
(\%)\end{array}$ & $\begin{array}{c}\text { Actual number } \\
\text { of plates } \\
\text { per ring }\end{array}$ & $\begin{array}{l}\text { Total coating } \\
\text { time per ring } \\
\text { (h) }\end{array}$ \\
\hline- & Ir & - & - & - & - & - & - & - \\
\hline 1 & 10.0 & 23 & 385 & 120 & 4200 & 85 & 4941 & 204 \\
\hline 2 & 10.0 & 23 & 371 & 120 & 4200 & 85 & 4941 & 236 \\
\hline 3 & 10.0 & 23 & 406 & 144 & 5040 & 85 & 5929 & 207 \\
\hline 4 & 10.0 & 23 & 406 & 168 & 5880 & 85 & 6918 & 236 \\
\hline 5 & 10.0 & 23 & 385 & 120 & 4200 & 85 & 4941 & 204 \\
\hline 6 & 10.0 & 23 & 385 & 144 & 5040 & 85 & 5929 & 245 \\
\hline 7 & 10.0 & 23 & 385 & 168 & 5880 & 85 & 6918 & 285 \\
\hline 8 & 10.0 & 23 & 406 & 168 & 5880 & 85 & 6918 & 236 \\
\hline 9 & 10.0 & 23 & 406 & 192 & 6720 & 85 & 7906 & 272 \\
\hline 10 & 10.0 & 23 & 406 & 192 & 6720 & 85 & 7906 & 272 \\
\hline 11 & 10.0 & 23 & 427 & 216 & 7560 & 85 & 8894 & 270 \\
\hline 12 & 10.0 & 23 & 427 & 216 & 7560 & 85 & 8894 & 270 \\
\hline 13 & 10.0 & 23 & 427 & 240 & 8400 & 85 & 9882 & 300 \\
\hline 14 & 10.0 & 23 & 399 & 240 & 8400 & 85 & 9882 & 358 \\
\hline 15 & 10.0 & 23 & 448 & 264 & 9240 & 85 & 10871 & 290 \\
\hline 16 & 10.0 & 23 & 448 & 288 & 10080 & 85 & 11859 & 322 \\
\hline 17 & 10.0 & 23 & 448 & 288 & 10080 & 85 & 11859 & 322 \\
\hline 18 & 10.0 & 23 & 469 & 316 & 11060 & 85 & 13012 & 320 \\
\hline 19 & 10.0 & 23 & 413 & 312 & 10920 & 85 & 12847 & 421 \\
\hline 20 & 10.0 & 23 & 469 & 336 & 11760 & 85 & 13835 & 344 \\
\hline Total & - & - & - & 4252 & 148820 & - & 175082 & 234 days \\
\hline
\end{tabular}

Table 5: Productivity estimate based on a single Iridium thin-film layer.

\section{DESIGN AND PREPARATION OF THE FACILITY}

The sputtering unit will be installed, calibrated and commissioned at cosine in 2018. Several preparations shall be considered such as, space for the deposition system, compatibility with the cleanroom standard, physical moving through doors, electricity/water/gas connections and process flow compatibility.

There are currently five clean rooms located at cosine, see floor plan in figure 6 . The most compatible cleanroom for installing the deposition system, in terms of the later mentioned items, is cleanroom 2, which is directly adjacent to technical rooms. This is shown in figure 6. Due to the maintenance of the deposition system, it is favorable to install most of the parts in a gray room connecting the door facing side of the system with cleanroom 2 , as illustrated in figure 7 . The foreseen flow of the SPO production is given below:

Cleanroom 1 Plates are received and inspected

Cleanroom 2 Plates are plasma cleaned, deposited with thinfilm materials and lifted

Cleanroom 3 Plates are cleaned and stacked

Cleanroom 4 Stacks are inspected and tested

Cleanroom 5 Reserved 


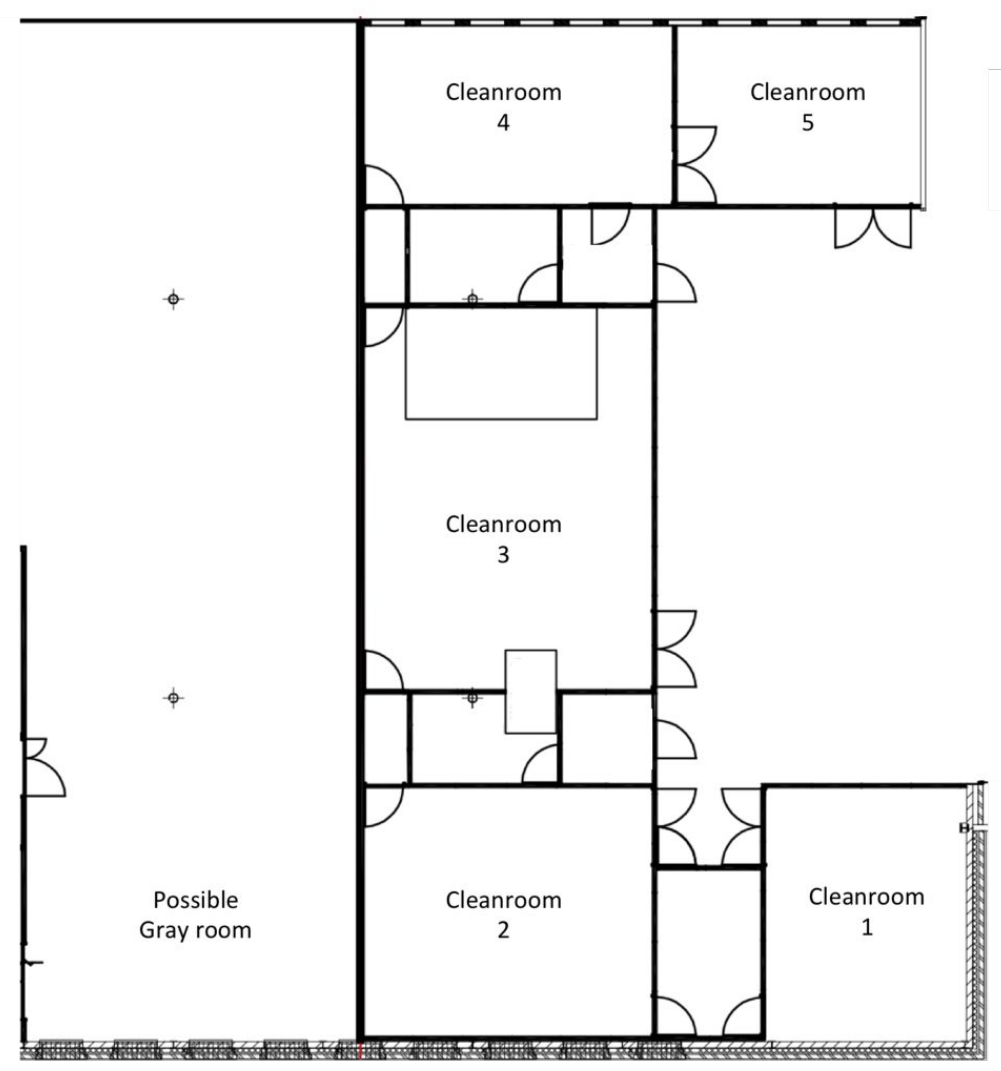

Figure 6: Floor plan of the cleanrooms located at cosine.

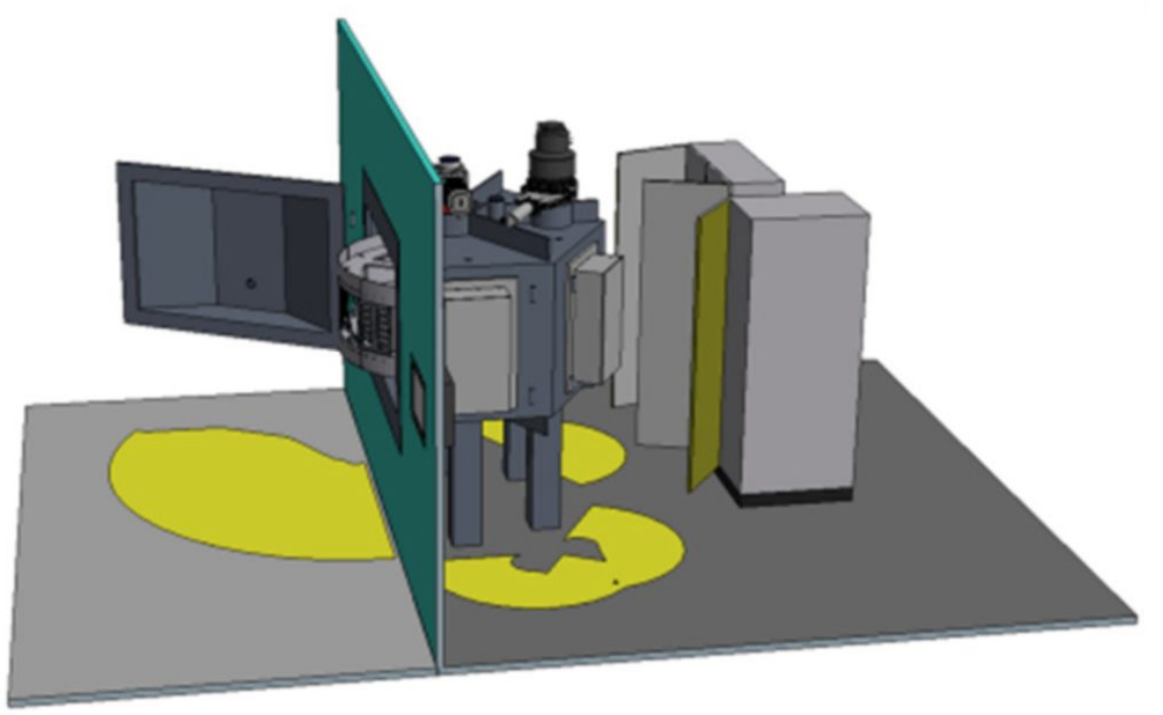

Figure 7: Illustration of the BS1200S installed in a gray-room with access to the drum from a cleanroom. (c) VON ARDENNE Corporate Archive 


\section{PRODUCT ACCEPTANCE TESTING}

Once the deposition system is completed, a factory acceptance test (FAT) will be carried out at Von Ardenne to demonstrate the compliancy with the requirements for the Athena thin-films. The FAT is designed by DTU Space based on investigating the thin-film parameter space within the current designs for the Athena mission. The test will consist of 12 different thin-films, a blend of single layers and multilayers of $\operatorname{Ir}$ and $\mathrm{B}_{4} \mathrm{C}$, shown in table 6 . The several thicknesses will provide information about the deposition rate, the stress induced by the thin-film, the surface and interface roughness, the thickness deviation and the density of the thin-films. These are all parameters that are well known in the deposition process performed at DTU Space and can be directly compared. Furthermore the same process parameters (pressure, target-substrate distance, power density and collimation) will be used. The thin-films will be deposited on super polished silicon substrates with a surface roughness $\sim 0.25 \mathrm{~nm}$ provided by International Wafer Service.

The characterization of the samples will be carried out at DTU Space with several characterization tools, such as $8.047 \mathrm{keV}$ X-ray reflectometry (XRR), Atomic Force Microscopy (AFM), Stylus profilometer and X-ray Photoelectron Spectroscopy (XPS), and at a synchrotron facility providing low energy XRR setups. With the XRR we will derive the thickness, interface/surface roughness and the composition. The AFM will be used to measure the surface roughness at confined areas of the samples. The stress level induced by the thin-film is measured with a Stylus profilometer and the density can be modeled with XPS measurements.

The thickness deviation will be determined through a Gauge R\&R method ${ }^{[19]}$. 


\begin{tabular}{|c|l|c|c|}
\hline Sample no. & Material & Thickness $(\mathrm{nm})$ & Maximum thickness deviation (\%) \\
\hline $\mathbf{1}$ & Boron Carbide & 5.0 & $\leq \pm 3$ \\
\hline $\mathbf{2}$ & Boron Carbide & 8.0 & $\leq \pm 3$ \\
\hline 3 & Boron Carbide & 20.0 & $\leq \pm 3$ \\
\hline $\mathbf{4}$ & Boron Carbide & 30.0 & $\leq \pm 3$ \\
\hline 5 & Iridium & 5.0 & $\leq \pm 3$ \\
\hline 6 & Iridium & 10.0 & $\leq \pm 3$ \\
\hline 7 & Iridium & 20.0 & $\leq \pm 3$ \\
\hline 8 & Iridium & 30.0 & $\leq \pm 3$ \\
\hline
\end{tabular}

\begin{tabular}{|c|c|c|c|}
\hline Sample no. & Material & Thickness (nm) & Maximum thickness deviation (\%) \\
\hline \multirow[t]{2}{*}{9} & Boron Carbide & 8.0 & $\leq \pm 3$ \\
\hline & Iridium & 10.0 & $\leq \pm 3$ \\
\hline \multirow[t]{20}{*}{10} & $\begin{array}{l}\text { Boron Carbide } \\
\text { (top) }\end{array}$ & 1.2 & $\leq \pm 5$ \\
\hline & Iridium & 1.8 & $\leq \pm 5$ \\
\hline & Boron Carbide & 1.2 & $\leq \pm 5$ \\
\hline & Iridium & 1.8 & $\leq \pm 5$ \\
\hline & Boron Carbide & 1.2 & $\leq \pm 5$ \\
\hline & Iridium & 1.8 & $\leq \pm 5$ \\
\hline & Boron Carbide & 1.2 & $\leq \pm 5$ \\
\hline & Iridium & 1.8 & $\leq \pm 5$ \\
\hline & Boron Carbide & 1.2 & $\leq \pm 5$ \\
\hline & Iridium & 1.8 & $\leq \pm 5$ \\
\hline & Boron Carbide & 1.2 & $\leq \pm 5$ \\
\hline & Iridium & 1.8 & $\leq \pm 5$ \\
\hline & Boron Carbide & 1.2 & $\leq \pm 5$ \\
\hline & Iridium & 1.8 & $\leq \pm 5$ \\
\hline & Boron Carbide & 1.2 & $\leq \pm 5$ \\
\hline & Iridium & 1.8 & $\leq \pm 5$ \\
\hline & Boron Carbide & 1.2 & $\leq \pm 5$ \\
\hline & Iridium & 1.8 & $\leq \pm 5$ \\
\hline & Boron Carbide & 1.2 & $\leq \pm 5$ \\
\hline & Iridium (bottom) & 1.8 & $\leq \pm 5$ \\
\hline \multirow[t]{20}{*}{11} & $\begin{array}{l}\text { Boron Carbide } \\
\text { (top) }\end{array}$ & 2.4 & $\leq \pm 5$ \\
\hline & Iridium & 3.6 & $\leq \pm 5$ \\
\hline & Boron Carbide & 2.4 & $\leq \pm 5$ \\
\hline & Iridium & 3.6 & $\leq \pm 5$ \\
\hline & Boron Carbide & 2.4 & $\leq \pm 5$ \\
\hline & Iridium & 3.6 & $\leq \pm 5$ \\
\hline & Boron Carbide & 2.4 & $\leq \pm 5$ \\
\hline & Iridium & 3.6 & $\leq \pm 5$ \\
\hline & Boron Carbide & 2.4 & $\leq \pm 5$ \\
\hline & Iridium & 3.6 & $\leq \pm 5$ \\
\hline & Boron Carbide & 2.4 & $\leq \pm 5$ \\
\hline & Iridium & 3.6 & $\leq \pm 5$ \\
\hline & Boron Carbide & 2.4 & $\leq \pm 5$ \\
\hline & Iridium & 3.6 & $\leq \pm 5$ \\
\hline & Boron Carbide & 2.4 & $\leq \pm 5$ \\
\hline & Iridium & 3.6 & $\leq \pm 5$ \\
\hline & Boron Carbide & 2.4 & $\leq \pm 5$ \\
\hline & Iridium & 3.6 & $\leq \pm 5$ \\
\hline & Boron Carbide & 2.4 & $\leq \pm 5$ \\
\hline & Iridium (bottom) & 3.6 & $\leq \pm 5$ \\
\hline \multirow[t]{20}{*}{12} & $\begin{array}{l}\text { Boron Carbide } \\
\text { (top) }\end{array}$ & 4.0 & $\leq \pm 3$ \\
\hline & Iridium & 6.0 & $\leq \pm 3$ \\
\hline & Boron Carbide & 4.0 & $\leq \pm 3$ \\
\hline & Iridium & 6.0 & $\leq \pm 3$ \\
\hline & Boron Carbide & 4.0 & $\leq \pm 3$ \\
\hline & Iridium & 6.0 & $\leq \pm 3$ \\
\hline & Boron Carbide & 4.0 & $\leq \pm 3$ \\
\hline & Iridium & 6.0 & $\leq \pm 3$ \\
\hline & Boron Carbide & 4.0 & $\leq \pm 3$ \\
\hline & Iridium & 6.0 & $\leq \pm 3$ \\
\hline & Boron Carbide & 4.0 & $\leq \pm 3$ \\
\hline & Iridium & 6.0 & $\leq \pm 3$ \\
\hline & Boron Carbide & 4.0 & $\leq \pm 3$ \\
\hline & Iridium & 6.0 & $\leq \pm 3$ \\
\hline & Boron Carbide & 4.0 & $\leq \pm 3$ \\
\hline & Iridium & 6.0 & $\leq \pm 3$ \\
\hline & Boron Carbide & 4.0 & $\leq \pm 3$ \\
\hline & Iridium & 6.0 & $\leq \pm 3$ \\
\hline & Boron Carbide & 4.0 & $\leq \pm 3$ \\
\hline & Iridium (bottom) & 6.0 & $\leq \pm 3$ \\
\hline
\end{tabular}

Table 6: Thin-film designs foreseen to be produced as part of the acceptance testing. 


\section{FORESEEN CALIBRATION OF DEPOSITION CHAMBER}

An important aspect of commissioning a new deposition chamber is to map the thin-film uniformity as a function of mirror position along the length of the magnetron ${ }^{[20]}$. Due to race tracks, magnetic field topography and geometric factors, the atom flux emitted along the length of the target varies, with the maximum atom flux being emitted from the center of the target. The procedure for mapping the uniformity is still under development however the main principle will be to place multiple mirror substrates on positions as shown in figure 8 for a single layer film deposition, following a thickness measurement. From an expected thickness variation along the target length, the film uniformity given as a function of mirror position in the chamber, will serve as base for the masking design. Following the uniformity mapping we will produce a mask and place it in the path between the target and the mirror plates resulting in a better thin-film uniformity along the target length.

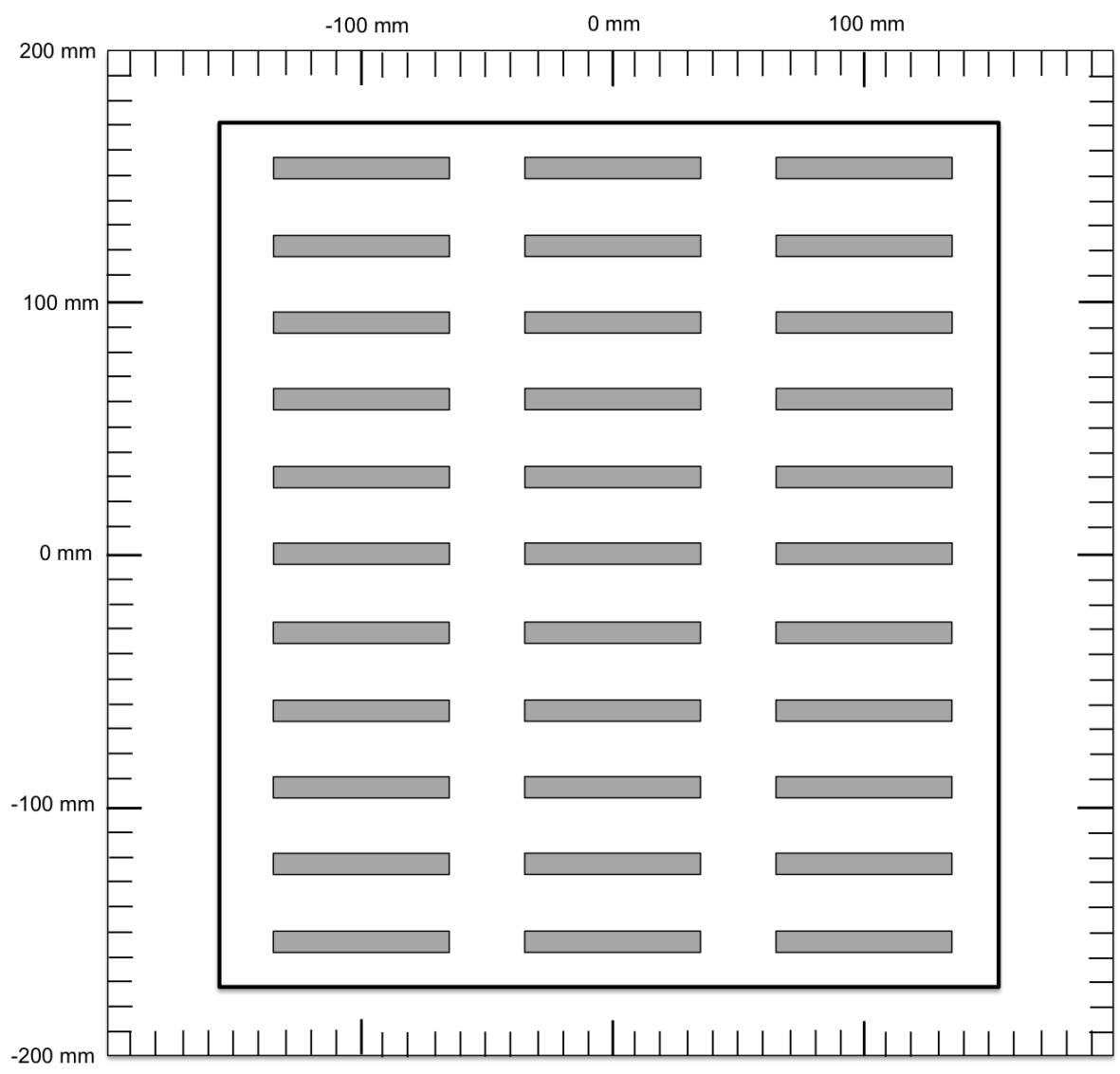

Figure 8: Foreseen mirror placement on the Von Ardenne carrier. The mirrors will cover the mounting area ensuring a uniformity better than $5 \%$.

\section{SUMMARY}

We reported on the most recent updates of the industrialization of the mirror plate coatings for the Athena mission. A thorough market research was performed, based on a list of thin-film requirements established by ESA, cosine and DTU Space. DC-magnetron sputtering has been selected as the thin-film deposition method due to the excellent record within X-ray optics.

We have through a public tender selected a supplier, Von Ardenne, who met the requirements and pursued the project actively. The drum coater BS1200S was designed based on the existing drum coater at DTU Space and provides the user a great flexibility in the sputtering process.

Based on the BS1200S carrier and magnetron dimensions we produced a productivity estimate of the most recent 
optics design for Athena. Three different productivity estimates are presented, one for a single bilayer design, one for an optimized multilayer design boosting the effective area of the telescope at $6 \mathrm{keV}$ and one for a single layer design, which is the minimum requirement for the Athena mission.

We presented the visual and technical layout of the future thin-film deposition facility for the Athena mission, which will be located in Warmond, The Netherlands.

The product acceptance testing will be carried out at Von Ardenne (FAT) and again at cosine (SAT) to verify the systems compliancy with the thin-film requirements. A full description of the testing and the methods for characterizing the results has been presented.

Ultimately, a foreseen calibration of the deposition chamber is given, once the SAT has been performed. This shall lead to a commissioning of the thin-film facility.

\section{ACKNOWLEDGEMENT}

This activity has been funded by the European Space Agency under contract AO/1-8285/15/NL/BW .

\section{REFERENCES}

1. K. Nandra and et al., "The hot and energetic universe: A white paper presenting the science theme motivating the athena+ mission," p. 19, 2013.

2. A. Jakobsen and et al., "Preliminary coating design and coating developments for athena," Proceedings of Spie, the International Society for Optical Engineering 8147(1), p. 81470T, 2011.

3. D. Ferreira and et al., "Athena optimized coating design," Proceedings of Spie, the International Society for Optical Engineering 8443, p. 84435L, 2012.

4. D. Ferreira and et al., "Coating optimization for the athena+ mission," Proceedings of Spie, the International Society for Optical Engineering 8861, p. 886112, 2013.

5. S. Massahi and et al., "Development and production of a multilayer-coated x-ray reecting stack for the athena mission," Proceedings of Spie, the International Society for Optical Engineering 9905, p. 99055P, 2016.

6. D. Ferreira and et al., "Development and characterization of coatings on silicon pore optics substrates for the athena mission," Proceedings of Spie, the International Society for Optical Engineering 8443, p. 84435E, 2012.

7. D. Ferreira and et al., "X-ray mirror development and testing for the athena mission," Proceedings of Spie, the International Society for Optical Engineering 9905, p. 99055K, 2016.

8. M. Bavdaz and et al., "The athena optics development," Proceedings of Spie, the International Society for Optical Engineering 9905, p. 990527, 2016.

9. M. Collon and et al., "Silicon pore optics for the athena telescope," Proceedings of Spie, the International Society for Optical Engineering 9905, p. 990528, 2016.

10. E. Wille and et al., "Mass production of silicon pore optics for athena," Proceedings of Spie, the International Society for Optical Engineering 9905, p. 990529, 2016.

11. D. Fletcher, "Guidelines for purchasing, installing and commissioning a vacuum web coater," Proceedings, Annual Technical Conference - Society of Vacuum Coaters , pp. 220-224, 1993.

12. P. Slane, "Axaf coating process selection study: Reflectivity measurements," 1992.

13. S. Swann, "Magnetron sputtering," Physics in Technology 19(2), pp. 67-75, 1988.

14. F. Christensen and et al., "Coatings for the nustar mission," Proceedings of Spie, the International Society for Optical Engineering 8147(1), p. 81470U, 2011.

15. J. Broughton and et al., "Titanium sputter deposition at low pressures and long throw distances," Ieee Transactions on Semiconductor Manufacturing 9(1), pp. 122-127, 1996.

16. "Lesker tech: Practical Process Tips." https://www.lesker.com/leskertech/archives/0g11m3h/ leskertech_v7_i1.pdf, 2010. [Online; accessed 3rd of July, 2017].

17. S. Massahi and et al., "Investigation of photolithography process on spos for the athena mission," Proceedings of Spie, the International Society for Optical Engineering 9603, 2015. 
18. D. Ferreira and et al., "Design, development, and performance of x-ray mirror coatings for the athena mission," Proceedings of Spie, the International Society for Optical Engineering, 2017.

19. M. S. A. M. W. Group and A. I. A. Group, Measurement systems analysis :, AIAG,, 2010.

20. N. Brejnholt, "Nustar calibration facility and multilayer reference database: Optic response model comparison to nustar on-ground calibration data," 2012. 